\title{
A Fobia e o Pânico em suas Relações com a Angústia'
}

\author{
Vera Lopes Besset ${ }^{2}$, Kátia Kac Nigri e \\ Leonardo Pinto de Almeida \\ Universidade Federal do Rio de Janeiro
}

\begin{abstract}
RESUMO - Nesse texto, objetivou-se indicar as relações da angústia com as manifestações patológicas da fobia e do pânico, demonstrando a adequação da proposta de intervenção terapêutica, dentro de uma perspectiva psicanalítica. Esse trabalho se refere a resultados parciais de pesquisa teórica sobre a angústia, onde o método utilizado é o de análise crítica dos conceitos. Neste, buscamos investigar a coerência entre as formulações teóricas de S. Freud e J. Lacan, já clássicas, com o que se observa na clínica hoje. Para tanto, valemo-nos da referência a dados da experiência clínica. A investigação aponta para a adequação da concepção psicanalítica da fobia e do pânico, pois confirma o caráter de substituto que tem o objeto temido. É esta mesma natureza que o torna permeável à ação da fala, no dispositivo de linguagem que é o da clínica psicanalítica.
\end{abstract}

Palavras-chave: fobia; pânico; angústia; clínica psicanalítica.

\section{Phobia and Panic Related to Anguish}

\begin{abstract}
The paper seeks to point out the relationship between anguish and the pathological manifestations of phobia and panic, and to demonstrate the adequacy of a proposal of therapeutic intervention within a psychoanalytical perspective. It reflects the parcial results of a theoretical research on anguish based on the formulations of Freud and Lacan. It is also reflexive of observations derived from present-day clinical practice. To this, data of clinic experience were used as reference. The results point to the usefulness of the psychoanalytic notion of phobia and panic since they confirm that the object of fear has a nature of substitute. This very nature makes the object fear permeable to the action of speech within the language device of the psychoanalytic clinic.
\end{abstract}

Key words: phobia; panic; anguish; psychoanalytical clinic.

A problemática da fobia preocupa os teóricos da psicanálise desde o início deste século e continua intrigando os pesquisadores nos dias de hoje. Observada com frequência no trabalho com crianças, comparece igualmente no tratamento de adultos, como queixa que nomeia um sofrimento. Atualmente, ganha relevo, ao receber novas 'roupagens' como a da 'fobia social', por exemplo.

Ao lado da fobia, tem-se os distúrbios que a clínica psiquiátrica denominou "doença" ou "síndrome do pânico". Estas "patologias do afeto" caracterizam a clínica no contemporâneo e ligam-se a manifestações da angústia. Tratase, mais precisamente, de "respostas" à angústia, cuja emergência coincidiria com a do desejo do sujeito. Desejo que, por acréscimo, é "calado" nos tratamentos medicamentosos cada vez mais aceitos na cultura (Orsine, 1999) e bastante eficazes, a partir de um certo ponto de vista. Neste contexto, objetiva-se demonstrar a adequação da proposta de intervenção terapêutica da psicanálise, de trabalho com a palavra, seguindo o percurso inaugurado por Freud (1890/1988).

O presente texto refere-se a resultados parciais da pesquisa, ora em andamento, sobre "Os afetos na teoria e na clínica psicanalítica: repensando Freud com Lacan” (Besset,

1 Este trabalho contou com apoio financeiro do CNPq na forma de projeto integrado e com a colaboração das alunas Fernanda Dias e Joana Deane, bolsistas de Aperfeiçoamento em Pesquisa e Iniciação Científica, respectivamente.

2 Endereço: Tv. Euricles de Matos, 24, Laranjeiras. CEP: 22240-001 Rio de Janeiro - RJ. E-mail: besset@openlink.com.br
1996). Nesta, a angústia é tomada como o afeto por excelência, aquele que "não engana", tal como aponta Lacan (1962-1963, p. 83). Isto supõe a concepção de um sujeito "afetado" em suas relações com o objeto que causa seu desejo. Objeto que porta em si uma ameaça e que determina o Zurückgedrängt, o 'a recalcar' (Lacan, 1991b, p. 422). Nesse caso, um perigo interno é similar a um perigo externo e o sujeito o evita do mesmo modo.

A proposta de tratar o afeto data do início da clínica freudiana, onde o mesmo foi entendido como causa do sofrimento psíquico, resto de energia não passível de escoamento (Freud, 1893/1987a, p. 120). No início, por intermédio da ab-reação ou catarse, onde se tratava de "liberar" esta "soma de excitação" aprisionada. Depois, pelo recurso da colocação em palavras, em substituição dessas à ação, o que inaugura o nascimento de uma nova clínica (Freud, 1893/1987b, p. 263). Trata-se, no final de um século marcado por sua invenção, de demonstrar como uma técnica que se baseia na palavra pode trazer efeitos no que diz respeito ao que, justamente, escapa a esta (Besset, 1999, p. 23). Para tanto, é necessário, em primeiro lugar, delimitar as similaridades de estrutura entre a experiência analítica e os fenômenos dos quais se ocupa. Note-se, porém, que a delimitação de uma técnica específicamente analítica não se esgota na especificação de 'instrumentos' que seriam próprios a esta, isto é, os vários modos de intervenção interpretativa do analista: pontuações, escansões, cortes, alusões, entre outros (Soler, 1995, p. 28). É preciso, ainda, que este procedimento terapêutico, 
para se nomear psicanálise, leve em consideração a transferência e a resistência (Freud, 1914/1989, p. 16) e se realize nos limites do campo da fala e da linguagem (Lacan, 1966).

\section{A Especificidade da Psicanálise}

Ao sujeito (Besset,1997) que chega angustiado, literalmente 'embaraçado' por seus afetos, o que se propõe na psicanálise? Nada mais do que o trabalho na transferência, proposta de elaboração daquilo que lhe escapa e aparece como "estranho". O sujeito vem, geralmente, "afetado", angustiado pelo encontro de algo de si que não reconhece como seu. Tal como o paciente de Freud, conhecido como o Homem dos Ratos, cujo horror ante um "prazer ignorado \{unbekennen por ele mesmo", o autor observa (Freud, 1909/1988b, p. 133). Se procura um psicanalista, vem em busca de um saber sobre seu sofrimento. Este saber marca distintamente esta proposta teórico-clínica no que concerne o trabalho com os afetos. Nela, trata-se de fazer falar, fazer passar "o afeto ao dito" (Soler, 1988). Somente assim se torna possível o acesso a uma verdade subjetiva. Verdade que diz respeito, com efeito, ao afeto que escapa ao sujeito, ao seu controle; saber que, justamente, aparece no lugar da verdade na fórmula do discurso analítico proposta por Lacan (1991, p. 151; 1991a, p. 151)

Saber que não se trata de extrair do sujeito, a verdade

$$
\frac{a}{\mathrm{~S}_{2}} \stackrel{\tilde{0}}{\Delta} \frac{\mathrm{S}}{\mathrm{S}_{1}}
$$

que estaria lá, a nossa espera, "dentro" dele, e que trataríamos de liberar (Barros, 1996). Afeto, nesse caso, que se confunde com o sujeito, afeto que seria possível 'descobrir' e extrair, tal como os mineiros com o ouro e as pedras preciosas. Na psicanálise, a proposta é a construção de um saber a partir do que se apresenta como inconsciente. Mas, o afeto, que é da ordem do signo, daquilo que 'faz sinal', acomodase mal nessa via de linguagem. Por quê, então, não lançar mão do recurso de uma outra proposta terapêutica, neste caso específico do afeto de angústia? Fundamentalmente, porque partimos de uma concepção de homem que o faz indissociável da ordem simbólica, que o funda enquanto humano e o distingue dos animais. Nesse contexto, entendemos que a própria necessidade, chamada biológica, é pervertida pela ordem do significante. Particularidade que se explicita, por exemplo, na anorexia, onde alguém pode se deixar morrer, recusando o alimento, contrariamente a uma ordem supostamente 'natural'. Assim, se o natural como dado 'bruto' desvinculado do significante é para nós da ordem do 'mito', a proposta de Lacan parece resumir a especificidade de nossa tarefa: verificar e não medir os afetos (1974, p. 37).

\section{Fobia e Pânico: Refletindo a Partir da Psicanálise}

Ao investigar a angústia, o estudo da fobia apresenta-se como incontornável (Pisetta, 1999). Ao se debruçar sobre a questão das relações entre os sintomas e a angústia, Freud retoma um caso de fobia em um menino (1909/1988a). A queixa é a recusa de andar na rua por se angustiar ante o cavalo. Mas, uma angústia é um sintoma? Isto somente se responde quando fica claro que esta "angústia frente ao cavalo", referida à expectativa angustiada de que "o cavalo o morderá", é substituta de uma angústia frente ao pai, por conflitos edipianos. É esse o traço que converte a angústia em sintoma sem separação entre os termos: "a substituição do pai pelo cavalo.” (Freud, 1926/1987, p. 99). Esse deslocamento justifica a denominação de sintoma ao sofrimento do menino. Para Freud, portanto, a definição de sintoma não coincide com a da medicina, onde este é signo, sinal de algo que não funciona bem, de uma disfunção (1917/1987).

A concepção do sintoma como implicando um processo de substituição, deslocamento, é algo coerente com a formulação de Lacan sobre o sintoma como metáfora do desejo (Lacan, 1966, p. 293), desejo metonímia do sujeito (Lacan, 1966, p. 623). Sintoma, então, regido pelas leis de articulação do significante na linguagem (p. 358), que coincidem com a lógica do inconsciente. Eis o que permite à psicanálise operar no tratamento das "patologias do afeto". Esse sintoma designa um objeto que é temido e que não é, absolutamente, aquele que se teme. Concordamos com Lacan que, em sua releitura da obra freudiana, discorda do mestre, para quem o cavalo comparecia no lugar do pai do menino. De fato, a angústia de Hans parece se referir ao medo de ser mordido, devorado pela mãe (Lacan, 1994, p. 228). Entretanto, tal medo remete, em última análise, à angústia de castração (Freud, 1926/1987 e Lacan, 1962-63).

Ao designar como sintoma o "medo" da fobia, Freud aponta para a formação de compromisso implicada em sua construção, posto que por definição cada sintoma traz, a um só tempo, a satisfação pulsional e sua interdição (1926/1987). A especificidade do sintoma fóbico é de funcionar como uma proteção (p. 120) contra a angústia, como um posto avançado que previne, evitando sua chegada (Miller, 1987, p. 118). Freud é explícito, o perigo que se teme é pulsional, portanto somente percebido como "externo", embora de modo algum alheio ao sujeito. Castração cuja realidade se faz presente para o menino na visão do órgão feminino, ou da falta de órgão masculino que aí se revela. Mas, é somente como falo, significante da falta, que este ter/não ter incide sobre o psiquismo do sujeito e, assim, sobre a dimensão do ser (Besset, 1998). "Assim, o que falta à mãe, o que falta à mulher, simboliza o que se pode perder. $\mathrm{O}$ falo adota, então, a função significante dessa perda" (Dias, 1999, p. 4).

$\mathrm{O}$ extrato de um caso clínico atendido em consultório deve explicitar melhor o que se indica na teoria ${ }^{3}$. Uma jovem mulher apresentando o sintoma fóbico, "medo de elevador", não consegue se lembrar de como e quando seu sin-

3 Os dados clínicos para análise de pesquisa se originam, em sua maioria, de relatos de casos publicados por autores reconhecidos no campo. Algumas vezes, porém, os dados se originam da experiência clínica dos integrantes do grupo de pesquisa, seja em prática privada ou institucional. O relato citado refere-se a caso clínico de responsabilidade da autora principal do texto. 
toma surgiu. Com muita dificuldade e aos poucos, seu esforço de rememoração a conduz a lembranças que se relacionam a sua vida sexual. Recentemente, instigada por um de seus namorados, fez menção a algo com qual havia se acomodado até hoje: a frigidez. Em seu relato, especifica-se a repulsa à relação sexual, o temor desta. $\mathrm{O}$ medo de elevador se esclarece melhor, ao mesmo tempo que cede em intensidade, ao ser evocada a similaridade entre o movimento de sobe e desce desse 'instrumento', que serve para o deslocamento de pessoas, e aquele do órgão do qual depende a efetivação do ato implicado na citada relação. Esse é um caso que indica, igualmente, a adequação da formulação lacaniana sobre o objeto fóbico como suplência a uma lei paterna, de interdição, que se marcou por uma carência do pai simbólico (Lacan, 1994, p. 228).

Antes de concluir, uma palavra sobre o pânico, que se aborda aqui com o intuito de apontar as relações entre as patologias, digamos, contemporâneas, com a angústia. $\mathrm{O}$ interesse é lembrar que a psicanálise tem algo a dizer sobre este sintoma que foi alçado à categoria de "doença", aplacando muitas vezes a angústia de alguns, ao nomear o que lhes faz sofrer (Calligaris, 1999). O pânico nada mais é que uma nova "forma", nem tão nova assim, para a crise de angústia. Deixemos falar a clínica, nos idos tempos do final do século XIX, quando a psicanálise, com a histeria, se construía. É o caso de uma moça, de uns dezoito anos, que se dirigiu a Freud durante as férias deste, ao saber que se tratava de um médico. Pede-lhe ajuda, pois seus "nervos" estavam ruins, apesar do remédio que lhe receitara um outro profissional. Julgando estar "novamente às voltas com as neuroses", visto a aparência sadia, mas infeliz da jovem, Freud (1893/1974) lhe faz algumas perguntas:

Relato a conversa que se seguiu entre nós tal como ficou gravada em minha memória, e não alterei o dialeto da paciente.

- Bem, e de quê você sofre?

- Sinto muita falta de ar. Nem sempre. Mas, às vezes ela me apanha de tal forma que acho que vou ficar sufocada. Isso não pareceu, à primeira vista, um sintoma nervoso. Mas logo me ocorreu que provavelmente era apenas uma descrição representando uma crise de angústia: ela estava destacando a falta de ar do complexo de sensações que decorrem da angústia e atribuindo uma importância indevida a esse fator isolado.

- Sente-se aqui. Como são as coisas quando vocêfica 'sem ar'?

- Acontece de repente. Antes de tudo, parece que há alguma coisa pressionando meus olhos. Minha cabeça fica muito pesada, há um zumbido horrivel e fico tão tonta que quase chego a cair. Então, alguma coisa me esmaga o peito a tal ponto que quase não consigo respirar.

- E não nota nada na garganta?

- Minha garganta fica apertada como se eu fosse sufocar.

- Acontece mais alguma coisa na cabeça?

- Sim, umas marteladas, o bastante para fazê-la explodir.

- Enão se sente um pouco assustada quando isso aconte- $c e$ ?

- Sim, acho que vou morrer. (Freud, 1893/1974)

A relação entre estes sintomas e uma situação traumática infantil, tentativas de sedução por parte de um tio, revelase possível, então. Mas, o que parece exemplar nesse extrato clínico é que a fala dessa jovem e a descrição que faz de seus males lembram bastante as queixas que comparecem com freqüência, hoje, nos consultórios, sejam eles de médicos, psicólogos ou psiquiatras. Esses transtornos, aparentemente contemporâneos, que Freud entendia como 'crises de angústia', teriam chances de se classificarem como "ataque de pânico", seguindo-se as diretivas do Manual de Diagnóstico e Estatístico dos Transtornos Mentais (DSM IV), que se transcrevem abaixo:

Um período de medo ou desconforto intenso, no qual quatro (ou mais) dos seguintes sintomas se desenvolveram abruptamente e atingiram o pico em dez minutos: palpitações, coração pulsando forte ou acelerado; sudorese; tremor; sensação de falta de ar ou de fôlego; sentimento de choque; dor no peito ou desconforto; náusea ou distenção abdominal ; tontura, instabilidade, sensação de cabeça oca ou desmaio; ausência de realidade (sentimento de irrealidade) ou despersonalização (estar desligado de si próprio); medo de perder o controle ou enlouquecer; medo de morrer; parestesia (sensação de torpor, zumbido; calafrios, ondas de calor. (DSM IV, conforme citado por Reys, 1999, p. 142)

Concluindo, é possível afirmar que a adequação do tratamento psicanalítico às patologias da fobia e do pânico depende da referência à concepção do sintoma como substituto e, ao mesmo tempo, manifestação da angústia. Angústia que aponta para o que se revela de singular no sujeito, o desejo que o anima e do qual não se trata de abdicar. Isto supõe a concepção de um inconsciente estruturado como uma linguagem, regido pela lógica do significante e restringe a experiência analítica ao campo da fala e da linguagem. Finalmente, esse percurso de pesquisa aponta para a importância de uma metodologia que, em nosso campo, possa incluir uma coleta sistemática de dados da clínica, ao lado de uma investigação teórico-conceitual. Fica a sugestão, que representa, certamente, um desafio metodológico para a pesquisa da teoria da clínica psicanalítica.

\section{Referências}

Barros, R.R. (1996, junho). Os afetos na psicanálise. Conferência de abertura das Jornadas do Ato Analítico sobre a Angústia, João Pessoa, Paraíba.

Besset, V.L. (1996). Os afetos na teoria e na clínica psicanalítica: repensando Freud com Lacan (projeto de pesquisa n. 523274/ 96-3). Brasília: CNPq.

Besset, V.L. (1997). “Quem sou eu?” A questão do sujeito na clínica psicanalítica. Arquivos Brasileiros de Psicologia, 4(49), 64 71 .

Besset, V.L. (1998). Adolescência, sexualidade e subjetividade. Psychê, 2(2), 71-78.

Besset, V.L. (1999). Interpretação: alcance da palavra, limites do 


\section{L. Besset \& cols.}

sujeito. Opção Lacaniana, 25, 23-25.

Calligaris, C. (1999, 25 de novembro). Deprimentes antidepressivos. Folha de São Paulo, Caderno 4, p. 9.

Dias, F.A. (1999). Algumas considerações sobre a fobia em Freud e Lacan (relatório de participação na pesquisa n. 523274/963). Brasília: CNPq.

Freud, S. (1974). Casos clínicos (J.L. Etcheverry, Trad.). Em J. Strachey. (Org.), Estudios sobre la histeria. Obras Completas (Vol. II, pp. 63-231). Amorrortu: Buenos Aires. (Trabalho original publicado em 1893)

Freud, S. (1987). 16a conferencia. Psicoanálisis y psiquiatría (J.L. Etcheverry, Trad.). Em J. Strachey (Org.), Obras Completas (Vol. XVI, pp. 223-234). Amorrortu: Buenos Aires. (Trabalho original publicado em 1917)

Freud, S. (1987). Inhibición, síntoma y angustia (J.L. Etcheverry, Trad.). Em J. Strachey (Org.), Obras Completas (Vol. XX, pp. 71-146). Amorrortu: Buenos Aires. (Trabalho original publicado em 1926)

Freud, S. (1987a). Señora Emmy von N (J.L. Etcheverry, Trad). Em J. Strachey (Org.), Estudios sobre la histeria. Obras Completas (Vol. II, pp. 71-123). Amorrortu: Buenos Aires. (Originalmente publicado em 1893)

Freud, S. (1987b). Sobre la psicoterapia de la histeria (J.L. Etcheverry, Trad.). Em J. Strachey (Org.), Estudios sobre la histeria. Obras Completas (Vol. II, pp. 261-309). Amorrortu: Buenos Aires. (Trabalho original publicado em 1893)

Freud, S. (1988a). Análisis de la fobia de un niño de cinco años (J.L. Etcheverry, Trad.). Em J. Strachey (Org.), Obras Completas (Vol. X, pp. 1-118). Amorrortu: Buenos Aires. (Trabalho original publicado em 1909)

Freud, S. (1988b). A propósito de un caso de neurosis obsesiva (J.L. Etcheverry, Trad.). Em J. Strachey (Org.), Obras Completas (Vol. X, pp. 119-249). Amorrortu: Buenos Aires. (Trabalho original publicado em 1909)

Freud, S. (1988). Tratamiento psíquico (tratamiento del alma) (J.L. Etcheverry, Trad.). Em J. Strachey (Org.), Obras Completas (Vol. I, pp. 111-132). Amorrortu: Buenos Aires. (Trabalho ori- ginal publicado em 1890)

Freud, S. (1989). Contribución a la historia del movimiento psicoanalítico (J.L. Etcheverry). Em J. Strachey (Org.), Obras Completas (Vol. XIV, pp. 1-64). Amorrortu: Buenos Aires. (Trabalho original publicado em 1914)

Lacan, J. (1962-1963). L'angoisse, Séminaire X. (mimeo não-publicado).

Lacan, J. (1966). Écrit. Paris: Seuil.

Lacan, J. (1974). Télévision. Paris: Seuil.

Lacan, J. (1991a). Du mythe à la structure. Em J.-A. Miller (Org.), Le Séminaire de Jacques Lacan (Livre XVII, pp. 137-153). Paris: Seuil.

Lacan, J. (1991b). L'angoisse dans son rapport au désir. Em J.-A. Miller (Org.), Le Séminaire de Jacques Lacan (Livre VIII, pp. 419-431). Paris: Seuil.

Lacan, J. (1991c). La présence réelle. Em J.-A. Miller (Org.), Le Séminaire de Jacques Lacan (Livre VIII, pp. 293-307). Paris: Seuil.

Lacan, J. (1994). Du complexe de castration. Em J.-A. Miller (Org.), Le Séminaire de Jacques Lacan (Livre IV, pp. 215-230). Paris: Seuil.

Miller, J.A. (1987). Percurso de Lacan, uma introdução. Rio de Janeiro: Jorge Zahar.

Pisetta, M.A.M. (1999). Da angústia ao recalque numa passagem pela fobia. Dissertação de Mestrado, Universidade Federal do Rio de Janeiro, Rio de Janeiro.

Orsine, E.C.F. (1999). O país dorme nos braços da farmacologia. Dora, Psicanálise e Cultura, 2(2), 17-18.

Reys, B.N. (1999). Angústia e fobia: pontuações sobre a síndrome do pânico. Escola Letra Freudiana. Hans e a Fobia, 24(XVIII), 141-148.

Soler, C. (1988). Affect et savoir. Revue de La Cause Freudienne, 10, 66-71.

Soler, C. (1995). Interpretação: as respostas do analista. Opção Lacaniana, 13, 20-38. 